$\mathrm{DE}$

M E D I C I N A

T R O P I C A L

$\mathrm{DE}$

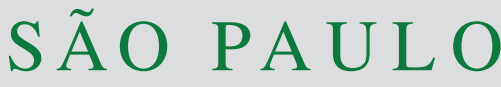

JOURNAL OF THE SÃO PAULO INSTITUTE OF TROPICAL MEDICINE

(1)Universidade de São Paulo, Instituto de Medicina Tropical de São Paulo, Laboratório de Imunopatologia - LIM-06, Setor de Biologia Estrutural, São Paulo, São Paulo, Brazil

(2)Universidade de São Paulo, Instituto de Medicina Tropical de São Paulo, Laboratório de Imunologia, LIM-48, São Paulo, São Paulo, Brazil

(3) Universidade de São Paulo, Faculdade de Medicina, Departamento de Dermatologia, Laboratório de Investigação Médica em Dermatologia e Imunodeficiências - LIM56, São Paulo, São Paulo, Brazil

(4) Universidade de São Paulo, Faculdade de Medicina, Departamento de Patologia, São Paulo, São Paulo, Brazil

(5)Universidade de São Paulo, Instituto de Medicina Tropical de São Paulo, São Paulo, São Paulo, Brazil

(6)Universidade de São Paulo, Instituto do Coração, Setor de Estudo da Inflamação, São Paulo, São Paulo, Brazil

(7)Instituto Adolfo Lutz, Laboratório de Microscopia Eletrônica, São Paulo, São Paulo, Brazil

${ }^{(8)}$ Instituto Butantã, Laboratório de Biologia Celular, São Paulo, São Paulo, Brazil

(9)Universidade de São Paulo, Faculdade de Odontologia de Bauru, Departamento de Ciências Biológicas, Disciplinas de Histologia e Embriologia, Bauru, São Paulo, Brazil

Correspondence to: Antonio Sesso Universidade de São Paulo, Instituto de Medicina Tropical de São Paulo, Laboratório de Imunopatologia - LIM-06, Av. Dr. Enéas de Carvalho Aguiar, 470, Prédio II, $2^{\circ}$ andar, CEP 05403-000, São Paulo, SP, Brazil Tel: $+55113061-7061$

E-mail: antses88@uol.com.br

Received: 30 June 2017

Accepted: 12 September 2017

\section{Bacteria arise at the border of mycoplasma-infected HeLa cells, containing cytoplasm with either malformed cytosol, mitochondria and endoplasmic reticulum or tightly adjoined smooth vacuoles}

\author{
Antonio Sesso', Edite Hatsumi Yamashiro-Kanashiro², Liã Bárbara \\ Arruda $^{3,4,5}$, Joyce Kawakami ${ }^{6}$, Maria de Lourdes Higuchi ${ }^{6}$, Noemia Mie Orii ${ }^{3}$, \\ Noemi Nosomi Taniwaki ${ }^{7}$, Flávia Mendes da Cunha Carvalho', Mariane \\ Pereira Brito ${ }^{1}$, Maiara Gottardi', Sylvia Mendes Carneiro ${ }^{8}$, Rumio Taga ${ }^{9}$
}

\section{ABSTRACT}

A study with transmission electron microscopy of mycoplasma-contaminated HeLa cells using five cell donors referred to as donors A, B, C, D and E, observations are herein presented. Experiments performed with cells from donors B, C and D, revealed the presence of Mycoplasma hyorhinis after PCR and sequencing experiments. Bacteria probably originated from a cytoplasm with compacted tiny granular particles replacing the normal cytosol territories, or from the contact with the cytoplasm through a clear semi-solid material. The compact granularity (CG) of the cytoplasm was crossed by stripes of smooth and rough endoplasmic reticulum cisternae. Among apparently normal mitochondria, it was noted, in variable proportions, mitochondria with crista-delimited lucent central regions that expand to and occupied the interior of a crista-less organelle, which can undergo fission. Other components of the scenarios of mycoplasma-induced cell demolition are villus-like structures with associated 80-200 $\mathrm{nm}$ vesicles and a clear, flexible semi-solid, process-sensitive substance that we named jam-like material. This material coated the cytoplasmic surface, its recesses, irregular protrusions and detached cytoplasmic fragments. It also cushioned forming bacteria. Cyst-like structures were often present in the cytoplasm. Cells, mainly apoptotic, exhibiting ample cytoplasmic sectors with characteristic net-like profile due to adjoined vacuoles, as well as ovoid or elongated profiles, consistently appeared in all cells from the last four cell donors. These cells were named "modified host cells" because bacteria arose in the vacuoles. The possibility that, in some samples, there was infection and/or coinfection of the host cell by another organism(s) cannot be ruled out.

KEYWORDS: Mycoplasma. Endoplasmic reticulum. Mitochondria. Cytosol.

\section{INTRODUCTION}

In 1898 , Nocard and Roux ${ }^{1}$ cultivated the causative agent of bovine pleuropneumonia. This organism was later identified as a novel type of bacteria devoid of a cell wall, named mycoplasma². Mycoplasma, a genus of the class Mollicutes, are the smallest (240 to $700 \mathrm{~nm}$ ) replicating organisms, with a genome size ranging from $580 \mathrm{~kb}$ to $2200 \mathrm{~kb}$, containing 464 to 1,760 genes that primarily code for the synthesis of nucleic acids and molecules necessary for survival and replication. Mycoplasma morphology observed in contaminated cells varies from an elongated bacillus-like shape to ellipsoid, ovoid, circular or curved dumbbell 
shapes of various thicknesses and lengths. For example, bovine mycoplasma, observed under transmission electron microscopy (TEM), may present uncommon shapes and sizes $^{3,4}$. In contaminated cell cultures or in tissues such as those of the mammalian airway, the submembranous layer of bacteria has often a variable density with a granular filamentous aspect and a lighter central region. When cultivated in special broth, mycoplasma exhibits various shapes other than the classical ovoid, circular and bacillus forms. They frequently lack the clear central part seen in bacteria that infect host cells and may exhibit generalized dense granularity. When recently inoculated in cultured cells, they appear as dense, dark, and often bacillus or curved dumbbell-like formations ${ }^{5}$. Most mycoplasma content resides within its membrane. In two strains of mollicutes, the measured composition of the membranes was $54 \%$ protein, $36 \%$ lipid and $6 \%$ carbohydrate $^{6}$. The minute genome of mycoplasma accounts for its minimal energetic and structural biosynthesis capabilities. Thus, mycoplasma must depend on external nutrients. They encompass some 200 species, approximately 14 of which are parasites. The majority is of commensals, and several are saprophytes. Not all mycoplasma species grow in common culture media. Mycoplasma that replicate only or preferentially in host cells are parasites, responsible for infecting cultured cells worldwide and eukaryotic cells of most multicellular organisms. The idea that mycoplasma are primarily parasites of the cell surface has prevailed for many years ${ }^{7}$. However, mycoplasma from several strains can penetrate host cells and persist intracellularly for at least 7 days $^{8}$. Immunofluorescence microscopy revealed forms of Mycoplasma gallisepticum (M. gallisepticum) outside and inside host cells ${ }^{9}$. Kikkawa et al. ${ }^{10}$ noted a low-grade intracellular persistence of live forms of $M$. fermentans after treatment of infected human leukemic cells with monoclonal antibodies that exposed the parasite to the killing action of human complement factors. Recent findings have further shown that mycoplasma can reside inside host cells. The intracellular forms of M. hominis inoculated in HeLa cells co-localized with proteins of the cell endosomal system, and the parasites established a chronic infection ${ }^{11}$. M. bovis can also invade, survive and multiply inside primary embryonic calf turbinate cells $^{3,4}$. Mycoplasma can be promoters or aggravating factors of many pathologies. They induce distress in humans and many other types of organisms, including mammals, poultry ${ }^{12}$ and fish ${ }^{13}$. Plants are plagued by mycoplasma-like organisms ${ }^{14}$. Not rarely Mollicutes that do not belong to the genus mycoplasma are referred to as mycoplasma as they were known before the new classification.
The present observations derive from attempts to identify a lineage of HeLa cells that is not contaminated by mycoplasma to perform structural studies of HeLa cells undergoing mitochondrial permeability transition promoted by staurosporine. In addition to the originally studied cells, nominated cells from cell donor $\mathrm{A}$, which originated the mentioned project, four other lineages obtained successively from four cell donors were examined under transmission electron microscope. It was not our intention to study the cytopathic action of mycoplasma in HeLa cells. The successive novel findings of structural lesions in the cells from cell donors $\mathrm{B}$ and $\mathrm{C}$ with nearby membrane-less bacteria, led us to expand the search for non-mycoplasmacontaminated HeLa cells. Systematic search for HeLa cells devoid of or with minimal amount of mycoplasma is not a novelty. In 1971, Franke and Scheer ${ }^{15}$, in order to carry out observations on the special cisternal differentiation of the smooth endoplasmic reticulum and on the incidence of annulate lamellae in HeLa cells, selected only cell cultures with less than one bacterium "mycoplasmataceae", then referred to as Pleuropneumoniae-Like Organisms (PPLO) per one hundred HeLa cells.

Here we show observations obtained in cells from three cell donors (B, C and D). From cell donor B, several cell batches were used, some of which showed cytopathic structural lesions of importance eventually ascribable to mycoplasma, but that did not typically contain the bacterial forms. Some of these samples devoid of typical bacterial forms are under study to detect whether other(s) organism(s) is(are) infecting host cells. Preliminary results obtained in HeLa cells heavily infected with mycoplasma revealed marked alterations in the endoplasmic reticulum (ER) and Golgi apparatus membranes in apoptotic cells, but also in the non-apoptotic ones ${ }^{16}$. Expanding upon these initial observations, we observed in samples from most cell donor's mycoplasma inflicted cytoplasmic alterations compromising the cell periphery, as the appearance of villus-like elements with associated 80-200 nm diameter vesicles. In markedly infected cells, one notes a jelly-like substance, which we refer to as jam-like material, coating a cytoplasm that exhibits a malformed endoplasmic reticulum, mitochondria and the cytosol region. In most cases, bacteria seem to be formed at the peripheral cytoplasm in contact with the jam-like material. A cell with a peculiarly altered phenotype was noted among the cells from all the last four cell donors. Such cell exhibits net-like cytoplasmic regions due to the tight aggregation of vacuoles with ovoid or elongated profiles. Eventually, the adjoined vacuoles fill all the cytoplasmic space. Because bacteria are noted inside the vacuoles these cells are designated as modified host cells. Bacteria formed in the vacuoles are extruded from the host cell. 
In forthcoming papers, more complete information will appear on the behavior of villus-like elements and the 80-200 $\mathrm{nm}$ diameter vesicles and the mitochondria in the mycoplasma-infected cells.

\section{MATERIAL AND METHODS}

Initially, cells received from five different cell donors exhibiting different degrees of cytoplasmic structural lesions caused by probable mycoplasma infection. Searching retrospectively, we noted that even cells from cell donor A exhibited structural lesions and remnants of cyst-like profiles. In some cellular cultures from donor B and cells from donors $\mathrm{C}$ and $\mathrm{D}$ exhibited typical bacterial forms of mycoplasma. Polymerase Chain Reaction (PCR) assays to detect mycoplasma gave strong positive reactions in the tested samples from cell donors B, C and D. Sequencing experiments revealed the presence of Mycoplasma hyorhinis.

\section{Cells and drugs}

\section{Cells}

Cell donors A and C were from the Department of Microbiology of the Institute of Biomedical Sciences of the University of São Paulo and the Laboratory of Cell Biology of the Ribeirão Preto Medicine School of the University of Sao Paulo, respectively. Cell donors B, D and E were from the Laboratory of Cell Culture of the Adolfo Lutz Institute in São Paulo, the Rio de Janeiro Cell Bank and the American Type Culture Collection (ATCC), respectively. Cell donors $\mathrm{D}$ and $\mathrm{E}$ work under biosafety level-2 conditions. The phenotypes of the cells varied widely in terms of the structural responses of infected cells when exposed to the kinase inhibitor staurosporine. In the following experiments using cells from donors $\mathrm{B}(\mathrm{sB}), \mathrm{C}(\mathrm{sC})$ and $\mathrm{D}(\mathrm{sD})$, the staurosporine concentration and the corresponding time of exposure to the cells are indicated. The number of samples is in parentheses; the experiments performed with cells from donor $\mathrm{B}$ consisted of trials using one or more concentrations of staurosporine for a single or various lengths of time. Each experiment included a control sample that was not exposed to the drug. The protocols were designed to evaluate the appearance of the mitochondrial permeability transition in the initial stages of apoptosis and included flow cytometry, fluorescence microscopy and transmission electron microscopy analyses. In the following experiments, the number of repetitions are in parentheses. Cells from donor B: Staurosporine $0.1 \mu \mathrm{M} / 2-3 \mathrm{~h}(7), 0.1 \mu \mathrm{M} / 4-5 \mathrm{~h}$ (2), $0.1 \mu \mathrm{M} / 6 \mathrm{~h}(7), 0.1 \mu \mathrm{M} / 16 \mathrm{~h}(1), 0.1 \mu \mathrm{M} / 24 \mathrm{~h}(1), 0.2 \mu \mathrm{M} / 6 \mathrm{~h}$ (1), $0.5 \mu \mathrm{M} / 2-3 \mathrm{~h}$ (11), $0.5 \mu \mathrm{M} / 4-5 \mathrm{~h}(10), 0.5 \mu \mathrm{M} / 6 \mathrm{~h}$ (3), $1.0 \mu \mathrm{M} / 2-3 \mathrm{~h}(5), 1.0 \mu \mathrm{M} / 4-5 \mathrm{~h}$ (2), $1.0 \mu \mathrm{M} / 6$ h (4),
$1.2 \mu \mathrm{M} / 2-3 \mathrm{~h}$ (1), $2.0 \mu \mathrm{M} / 6 \mathrm{~h}$ (1), controls (21). Cells from donor C: staurosporine $0.5 \mu \mathrm{M} / 4-5 \mathrm{~h}(6)$, controls (4). Cells from donor $\mathrm{D}$ : staurosporine $0.1 \mu \mathrm{M} / 6 \mathrm{~h}(23), 0.2 \mu \mathrm{M} / 6 \mathrm{~h}$ (11), $0.3 \mu \mathrm{M} / 6 \mathrm{~h}$ (17), $0.9 \mu \mathrm{M} / 6 \mathrm{~h}$ (17), controls (25). Cells from donor $\mathrm{C}$, frozen in 2014, were thawed in 2015 for PCR analysis and in 2016 for electron microscopy of the cells separated from the culture flask supernatant: staurosporine $0.4 \mu \mathrm{M} / 5 \mathrm{~h}$ (3), $0.4 \mu \mathrm{M} / 6 \mathrm{~h}$ (2), $0.9 \mu \mathrm{M} / 5 \mathrm{~h}$ (2), controls (7). Subcultures from cells of cell donors B, C and D were frozen in 2014 and some have been thawed in 2015, 2016 and 2017 for structural and PCR exams.

\section{Cell culture, fixation and embedding}

Cells from donors $\mathbf{B}$ and $\mathbf{C}$ were cultured in Dulbecco's Modified Eagle's Medium (DMEM) with $10 \%$ calf bovine serum and maintained in an incubator at $37^{\circ} \mathrm{C}$ with $5 \%$ $\mathrm{CO}_{2}$. The initially arrived cells from donor $\mathbf{D}$ and some previously frozen samples from cell donors $\mathbf{B}$ and $\mathbf{C}$ and cultured in DMEM medium were handled in a biosafety level 2 facility at the Institute of Tropical Medicine of São Paulo of the University of São Paulo. In this laboratory, cells were cultured in an incubator at $37^{\circ} \mathrm{C}$ with $5 \% \mathrm{CO}_{2}$ and with a UV sterilizing circulating air model MCO-170AICUVL (Panasonic).

For fixation, $4 \times 10^{5}$ cells were centrifuged at $100 \times \mathrm{g}$ for $10 \mathrm{~min}$. and the pellets were immersed in $1.2 \mathrm{~mL}$ of $3 \%$ glutaraldehyde in phosphate-buffered saline (PBS) at $\mathrm{pH} 7.4$ for $2 \mathrm{~h}$ on ice. After washing twice with PBS, the pellets were incubated in $400 \mu \mathrm{L}$ aqueous $3 \%$ hexapotassium ferrocyanide plus $400 \mu \mathrm{l}$ aqueous $2 \%$ osmium tetroxide at RT. Vials were manually agitated every $15 \mathrm{~min}$. during the fixation periods. After three passages in PBS, pellets were exposed to $2 \%$ uranyl acetate overnight, and embedded in either Epon or Araldite.

\section{Embedding Procedure 1 in Epon}

The initial dehydration was performed using a series of ethanol concentrations followed by immersing 4 times in $100 \%$ acetone for $10 \mathrm{~min}$. and twice in a mixture of 1 volume of 100\% acetone plus 1 volume of Epon mixture under slow rotation for $3.5 \mathrm{~h}$. The pellet was transferred to pure Epon for $24 \mathrm{~h}$ at $20^{\circ} \mathrm{C}$ and then transferred to molds maintained at $60{ }^{\circ} \mathrm{C}$ for 3 days. The Epon mixture consisted of $16.4 \mathrm{~g}$ NMA, 7.6 g DDSA, 300.75 g DMP, and 27.1 g LX Epon.

\section{Embedding Procedure 2 in Araldite}

Samples were dehydrated in $30 \%$ acetone for $10 \mathrm{~min}$., $70 \%$ for $10 \mathrm{~min}$., $95 \%$ for $15 \mathrm{~min}$., and 4 times in $100 \%$ for 
$15 \mathrm{~min}$. Samples were then transferred to a 1:1 mixture of Araldite and $100 \%$ acetone and incubated for $3 \mathrm{~h}$ under slow rotation at RT. Samples were then placed in an Aralditeonly mixture at $37^{\circ} \mathrm{C}$ for $1 \mathrm{~h}$, followed by fixation at $60^{\circ} \mathrm{C}$ for $24 \mathrm{~h}$. The separated, embedded pellet was re-embedded in a mold filled with an Araldite mixture and left for three days at $60^{\circ} \mathrm{C}$. The Araldite-embedding mixture consisted of $11.4 \mathrm{~g}$ Araldite, $8.0 \mathrm{~g}$ DDSA, $0.6 \mathrm{ml}$ DMP 30 , and $0.05 \mathrm{~mL}$ dibutyl phthalate. The samples were examined using Jeol 1010 and Jeol 1020 electron microscopes at $80 \mathrm{kV}$.

\section{Separation of floating, detached cultured cells}

Pellets commonly containing both, cells that were adherent and cells from the supernatant revealed a conglomeration of apoptotic cells in certain regions of the thin sections, and the absence of apoptosis in other sectors. Such high concentrations of apoptotic cells possibly appeared in thin sections containing the top region of the pellet, which contains the smallest, lightest cells of the preparation, including apoptotic cells. From July 2015 onward, weeks after arrival of the first cell batch from cell donor $\mathrm{E}$ and in the ensuing exams, we centrifuged cells of the supernatant separately from the remaining adherent cells, which were detached using a trypsin-versene mixture. Using this procedure, we identified small apoptotic cells and a surprising number of modified host cells in the pelleted supernatant. Modified host cells were present even when the cytopathic structural lesions were infrequent and of minor intensity, namely, in staurosporine-treated cells.

Polymerase chain reaction (PCR) for detection of mycoplasma genomic DNA (extraction, amplification and sequencing)

In the initial PCR test, the examined cells that were adherent to the culture flask bottom were detached by trypsin-versene and are designated as assay one. Some PCR negative results using the ATCC kit led us to carry out another round of tests, referred to as assay two, this time scrapping the cells mechanically.

\section{Assay One}

The universal mycoplasma detection kit from ATCC indicates the presence of $M$. arginini, M. fermentans, $M$. hyorhinis, M. orale, M. pirum, M. salivarum and M. laidalvii. Genomic DNA of samples from donors B, frozen in 2013, and C and D, in 2014 and 2015, respectively, were analyzed. Total genomic DNA was extracted from $200 \mu \mathrm{L}$ of cultured cells $\left(10^{5}\right.$ cells) using a QIAamp DNA ${ }^{\circledR}$ mini kit (Qiagen ${ }^{\circledR}$,
Hilden, Germany) following the protocol provided by the manufacturer. Mycoplasma DNA was amplified by PCR using a Universal Mycoplasma Detection kit (АТCC ${ }^{\text {TM }}$, Manassas, VA, USA) in a total volume of $25 \mu \mathrm{L}$ containing $20 \mu \mathrm{L}$ of universal PCR Mix, $2.5 \mu \mathrm{L}$ of universal primers and $2.5 \mu \mathrm{L}$ of test sample. All reactions included negative and positive controls. PCR processing conditions followed the manufacturer's recommendation. Detection of amplification products was carried out by electrophoresis in 3\% agarose gels. Positive samples were sequenced by the Sanger method using the BigDye Terminator v3.1 cycle sequencing kit (Applied Biosystems, Thermo Fisher Brand, Foster City, CA, USA) and the same primers used in the PCR analysis. Sequencing reactions were analyzed on an ABI 3500 automated sequencer (Applied Biosystems, Thermo Fisher Brand, Foster City, CA, USA). Sequence analysis was performed to determine the identity of mycoplasma, and the sequence was submitted to a BLAST search of the GenBank database, and to phylogenetic analysis using the Neighborjoining (NJ) method (bootstrap test with 1,000 replicates) ${ }^{17}$. Samples from cell donors B, C, and D were examined at intervals two more times using only the PCR test kit.

\section{Assay Two}

In this assay, the sample from cell donor B was one with cytopathic cytoplasmic structural lesions in which no typical bacterial forms appeared under the transmission electron microscope. This sample gave negative PCR results for the presence of mycoplasma, in two successive tests, and is still under analysis. Also, recent PCR test using cells from donor D confirmed the presence of mycoplasma and these cells exhibited frequent presence of typical bacterial forms under the electron microscope. Formerly typical bacteria were infrequent in the cells from cell donor D. The Universal Mycoplasma Detection Kit (ATCC) was used following the manufacturer's instructions. Briefly, $10^{5}$ cells were harvested by scraping and were washed with PBS. The obtained pellet underwent lysis and $2.5 \mu \mathrm{L}$ of lysate were added to a PCR reaction mix containing Universal PCR Mix and of Universal Primers. PCR was carried out in a conventional thermocycler applying an annealing temperature touchdown technique, following manufacturer's recommendations. PCR products were visualized by electrophoresis in agarose gels stained with SybrSafe DNA Gel Stain (Invitrogen) under UV light.

\section{RESULTS}

The sample from cell donor A, some samples from cell donor $\mathrm{B}$ and the original samples from cell donors $\mathrm{C}$ and $\mathrm{D}$ 
and E occasionally displayed signs of having been exposed to drugs used to kill mycoplasma in cultured cells. Among and near the cells, they presented bundles of a peculiar sort of mycoplasma membrane-derived striated filamentous material resembling that one presented in the lower panel of Figure 5 from Vollenbroich et al. ${ }^{18}$.

The altered cytoplasmic structures suggestive of mycoplasma contamination vary in incidence and in intensity in each cell. These are cytoplasmic sectorial fragmentation and/or erosions often associated with the appearance of malformed villus-like elements and small vesicles with 80-200 $\mathrm{nm}$ diameter. There was cytosol replacement by a compact mass of tiny granules measuring around $5-8 \mathrm{~nm}$. These compact granularity $(\mathrm{CG})$ regions are crossed by irregular stripes of the endoplasmic reticulum. The more intense the cytopathic structural lesions of the host, the greater the incidence of mitochondria with a clear central region delimited by cristae or completely devoid of cristae and filled by the material that was initially central. A component of most scenarios of structurally injured host cell is the appearance of a semi-solid material that we refer to as jam-like material that coats the cytoplasm, villus-like elements, small vesicles and detached peripheral cytoplasmic fragments. In virtually all the samples examined, notably after the separation of the cells from the supernatant medium of the culture flask, we noted the presence of a phenotypically different cell whose cytoplasm in varying extensions had sectors occupied by worm-like or circular tightly adherent clear vacuoles that confer a net-like appearance to the region. These vacuoles may exhibit bacterial forms corresponding to mycoplasma. We named such cells as modified host cells. The appearance of circular or polygonal cyst-like formations occurred scarcely in mildly infected cells and were common when marked structural cytopathic alterations took place.

Cytopathic effects of staurosporine administration in non-apoptotic and in apoptotic mycoplasma-infected cells

Experiments with staurosporine in cells from donor B aimed at examining the mitochondrial structure in cells entering apoptosis induced by the drug. In each experiment with cells from donor B, we tested two to five different concentrations of staurosporine ranging from 0.1-1.2 $\mu \mathrm{M}$ for durations ranging from 1 to $6 \mathrm{~h}$. From cell donor D, staurosporine concentrations in most trials were $0.1 \mu \mathrm{M}$, $0.3 \mu \mathrm{M}$, and $0.9 \mu \mathrm{M}$. The adjoining table contains apoptotic indices of the staurosporine effects in the examined cells. To underline the differences between results obtained in cells from different cell donors, we choose from donors B and $\mathrm{D}$ only the values from cells exposed to staurosporine $0.1 \mu \mathrm{M} / 6 \mathrm{~h}$. From cell donor B, we separated as group $\mathrm{B} 1$ the highest apoptotic indices obtained. These values in group $\mathrm{B} 1$ are highly significantly different $(\mathrm{P}=0.01)$ from those obtained from cell donor D. All the cytopathic structural effects noted in contaminated cells were enhanced after staurosporine administration. In mildly infected cells, effects of the staurosporine dose were apparent in both apoptotic and non-apoptotic cells. When cells had signs of being markedly infected, even the smallest dose concentration and time of exposure produced intense structural cytopathic effects. In different experiments, the intensity of the apoptotic indices and of the associated structural cytopathic effects were more influenced by the status of host-parasite interaction mechanisms than the staurosporine concentration employed. In summary, it may be stated that the exposure of the mycoplasma-infected cells to the kinase blocker staurosporine amplified to varying degrees of pre-existing structural derangements of non-apoptotic and apoptotic cells. The number of apoptotic modified host cells also increases (Figures 7A-7G).

\section{Cytometric observations}

Staurosporine administration enhanced the reduction in cell size that occurs in mycoplasma-infected cells. Apoptosis itself reduces cell volume. However, the elevated incidence of non-apoptotic cells with signs of marked cytoplasmic loss caused by mycoplasma has also contributed to marked changes in the size of the nonapoptotic cells. Several of these cells exhibited a small cytoplasmic rim encircling the nucleus. We perceived this cell-size variation in mycoplasma-infected cells by noting the forward and side scatter parameters of the cells in the flow cytometer. An extremely variable number of infected non-apoptotic cells with cytoplasmic loss had sizes similar to or lower (Figure 2A) than those of apoptotic cells. Therefore, both apoptotic and nonapoptotic cells intermix in the size-dependent forward scatter chart positions (data not shown). As data on Table 1 may suggest, this information will have low value as a predictability source. This is one of the main reasons why the flow cytometry observations in mycoplasma-infected cells were discontinued.

Common peripheral profiles and cytoplasmic components of mycoplasma-infected cells

Different cell peripheries are shown in Figures 1A, 1C and $1 \mathrm{E}$ coexisting in cells from donors $\mathrm{B}, \mathrm{C}$ and $\mathrm{D}$. The crenelated profile pointed by the thick arrow (Figure 1C) 
Table 1 - Staurosporine effect on apoptotic indices from cells of different cell donors

\begin{tabular}{|c|c|c|c|c|c|c|}
\hline \multirow[t]{3}{*}{ Cell Providers } & \multicolumn{6}{|c|}{ Apoptotic Indices } \\
\hline & $\mathrm{n}$ & Mean \pm SEM ${ }^{*}$ & Extreme Values & Compariso & een groups ${ }^{\&}$ & Staurosporine treatment \\
\hline & & & & $\mathrm{B} \times \mathrm{C}$ & $P>0.05$ & \\
\hline \multirow[t]{3}{*}{ B } & 4 & $51 \pm 8.3$ & $27-61$ & $\mathrm{~B} \times \mathrm{B} 1$ & $P>0.05$ & All samples \\
\hline & & & & $\mathrm{B} \times \mathrm{D}$ & $P<0.05^{\star}$ & \\
\hline & & & & $\mathrm{B} 1 \times \mathrm{C}$ & $P>0.05$ & $0.5 \mu \mathrm{M} / 3 \mathrm{~h}$ \\
\hline \multirow[t]{2}{*}{ B1 } & 3 & $72 \pm 8.4$ & $58-78$ & $B 1 \times D$ & $P<0.01^{\star *}$ & $0.5 \mu \mathrm{M} / 6 \mathrm{~h}$ \\
\hline & & & & & & $1.0 \mu \mathrm{M} / 3 \mathrm{~h}$ \\
\hline \multirow{2}{*}{ C } & \multirow{2}{*}{3} & \multirow{2}{*}{$45 \pm 13.9$} & \multirow{2}{*}{$17-60$} & \multirow{2}{*}{$C \times D$} & \multirow{2}{*}{$P>0.05$} & $0.5 \mu \mathrm{M} / 4 \mathrm{~h}$ \\
\hline & & & & & & $0.5 \mu \mathrm{M} / 5 \mathrm{~h}$ \\
\hline D & 5 & $22 \pm 5.6$ & $4-38$ & - & - & $\begin{array}{c}\text { All samples } \\
0.1 \mu \mathrm{M} / 6 \mathrm{~h}\end{array}$ \\
\hline Controls & 14 & $2 \pm 0.4$ & $0-5$ & - & - & - \\
\hline
\end{tabular}

\#SEM= Standard Error of the Mean. ${ }^{\circledR}$ Comparisons between groups done with "t" tests.

was found in varying proportions in control cells from all the other donors. In infected cells, even control ones, cells not exposed to staurosporine exhibit detachment of peripheral cytoplasmic small fragments seen in various degrees at the border region of most cells (Figure 1E). Experiments in cells from donors A and B designed to study the mitochondria of staurosporine-induced apoptotic cells revealed that all the cytopathic effects appearing in infected control cells were consistently enhanced after staurosporine action. For this reason, cells from donor B received several assays different concentrations of staurosporine for varying exposure times. Cyst-like profiles (marked C in Figure 1D) and mitochondria with clear central regions are perceptible enlarging Figures 1A, 1B and 1E to 200-300\%. In an apoptotic modified host cell in Figure 1E, the extremities of the lines departing from the asterisk show remnants of the homogeneous material that filled all the vacuoles. This material is sensitive to the dehydration and the embedding stages of electron microscopic procedures. Eventually, residues of such material were retained in the extremities of the elongated vacuoles.

\section{Dissimilar mechanisms of bacteria emergence from the host cell periphery}

The profiles of bacteria near or adhering to the host cells varied in shape, size and number (panels in Figures 2, 3 and 4). In our preparations, a typical bacterial profile possesses a submembranous layer of dense granular-filamentous material (border of the profiles numbered as 5 in Figure 2A and $\mathbf{d p}$ in Figure 2C) and variable size, a clear central part (center of the profiles numbered as 5 in Figure 2A and $\mathbf{c c}$ in Figure 2C). When Mycoplasma hyorhinis and M. fermentans were added to cell cultures, they appeared elongated and markedly dense ${ }^{5}$. An undisclosed proportion of bacteria shown in Figures 2, 3 and 4 were generated locally, probably by binary fission. They have a dumbbell profile with a thin curved rod central region (arrowheads in Figure 2A and enclosed by dotted lines in Figure 4A and in the upper part of Figure 4B). Such profiles are commonly seen in various species of cultured mycoplasma. An untreated cell from donor B presented a most servile behavior of a host cell in the context of host-parasite relationship. An enlarged view of the scenario where villus-like structures seem to detach and transform into mycoplasma is in Figure 2A. The entire infected cell is represented in Figure 2B. In Figure 2A, number 1 marks dense emerging villus-like elements. Part of the fake villi appear to have detached and start to swell. The initially swollen forms are numbered as 2 . The two close, inclined, parallel lines interrupted by numbers 4 and 2 indicate, respectively, that the swelling is more pronounced in the distal portion of the former rod-like villus-simile appendage while the proximal part maintains a lower level of permeability. Similarly, left of this panel, diversely swollen upper and lower segments from a probable villuslike derived forming bacterium are indicated by letters $\mathbf{b}$ and a, departing respectively from a number 3 . Other villus-like formations visibly swell prior to complete disconnection from the host cell [pointed by the two dotted arrows on the left side]. The swelling proceeds through stages number 3 , 4 and 5 . The dense host cell cytoplasm is mostly formed by a compact granularity (CG). The curved dotted line on the right encloses a ramified dense villus-like element that has detached from the cytoplasm with a pedestal segment that is an inverted $Y$. The upper part of this branched profile appears as a thick U. Variants of such forms are relatively 

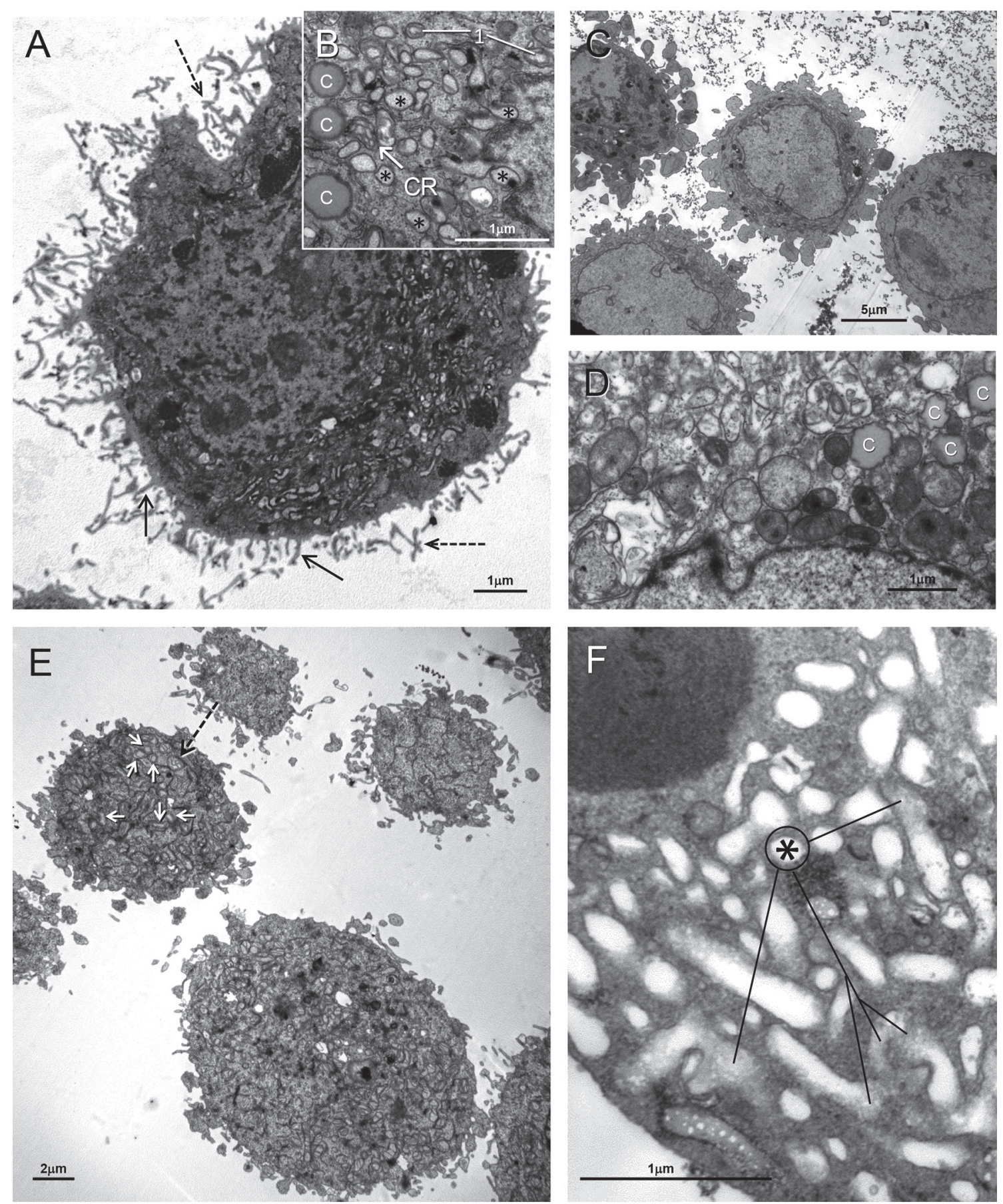

Figure 1 - Panel A - sC - Control. Emerging (arrows) and detaching (dotted arrows) villus-like elements. Panel B - sC - Control. Mitochondria with crista-delimited clear central region (lines departing from 10). Crista-less mitochondria (asterisks) devoid of cristae with the interior filled with lucent material. Mitochondria with irregularly disposed cristae, referred as crista remodeling (CR) (white arrow). Cyst-like profiles (C). Panel C - sB - Control. The three cells in the center and on the left have crenelated profiles. Panel D - sD - Control. Cyst-like profiles (C) are marked as C. Panel E - sD - Control. Cells profiles with detachment of small pieces of the peripheral cytoplasm. Mitochondria with clear central region (small white arrows). Crista remodeling (dotted arrow). Panel F - sD - Control. Apoptotic modified host cell. Lines from the asterisk indicate remnants of the material that filled the cytoplasmic vacuoles. At upper left a dense bloc of apoptotic chromatin

frequent, close to infected cells with nearby free bacteria, as that, a markedly swollen pedestal-like extremity of a possible bacterium, enclosed by a dotted ellipsoid is shown in Figure 3B. The nucleoli of this infected cell in Figure 2B are the largest yet seen in our preparations, contrasting with the thin, residual cytoplasm around the nucleus.

In Figure 2C, a thin amount of jam-like material holds bacterium marked as A connected to the cytoplasm. In the 


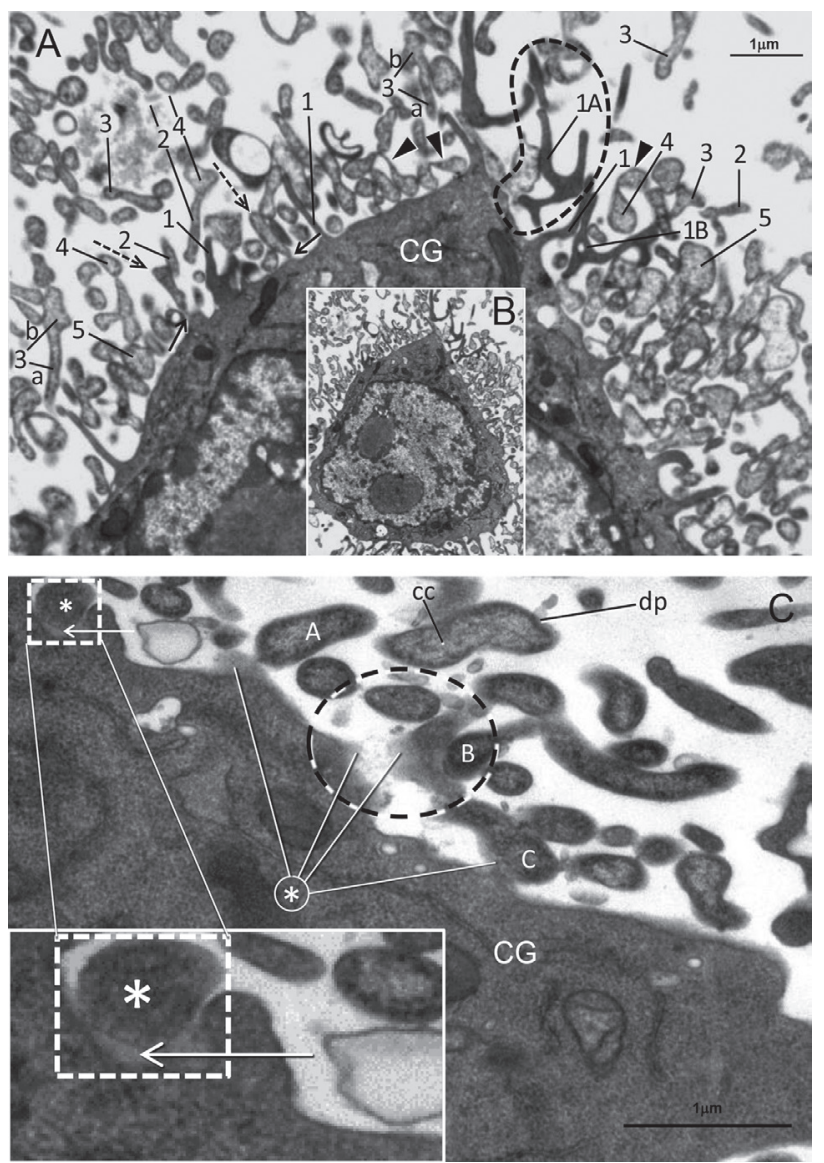

Figure 2 - Panel A - sB - Control. Enlarged part from Panel B. Dense, rod-like or -branched villus-like elements (1). Initial degree of swollenness (2). Emerging region (arrows) of loosely attached swelling villus -like elements (dotted arrows). Progressive swelling of the forms (numbers 3-5). From stage 2 onwards, the profiles can undergo fission (arrowheads). Markedly dense cytoplasm (CG). Panel B - The nucleoli of this cell are markedly enlarged. Panel C - sB - Staurosporine $0.1 \mu \mathrm{M} / 6 \mathrm{~h}$. Panel $\mathrm{C}$ of $\mathrm{sB}$ cells treated with $0.1 \mu \mathrm{M} / 6 \mathrm{~h}$ staurosporine. Detachment of a cytoplasmic piece mediated by splitting of the jam-like material (extremities of lines departing from the asterisk). Bacteria $\mathbf{B}, \mathbf{C}$ and $\mathbf{A}$ are -detaching from the cell. Dense periphery of the bacterium (dp) and their clear central (cc). The structure marked by an asterisk is cushioned by jam-like material (white arrow at upper left dotted rectangle that is enlarged below)

center of the figure, a dotted ellipsoid encloses a region just detached from the cytoplasm. The two central lines departing from the asterisk marks jam-like coated parts have been pulled apart. A possible newly-formed bacterium marked as $\mathbf{B}$ is attached to the removed cytoplasmic fragment by jam-like material and has the other extremity connected with jam-like material to other bacterium-like profile. Bacterium $\mathbf{C}$ appears to be detaching from the cytoplasm. Its right part is adherent to the coat of jammaterial below and its lower concavity seems to fit into the slightly bulged cytoplasmic region below. The upper and middle cytoplasmic border of the host cell has slightly curved depressions, which seems to derive from detachment of bacteria, many of which are curved, free in the field.

Bacteria also arise from the cell border in close connection with jam-like material

A telling connection of a nascent bacterium with its cushion of jam-like material, indicated by the line originated in the asterisk, appears in Figure 3A. This image suggests that the formation of the bacterium is closely dependent of its association with the subjacent jam-like material. This image and those in Figures 3B and 3D are cells from cell donor D. Small white circles denote bacteria in Figure 3B that are also perceived enlarged in Figure 3D. The close proximity between bacteria and various sized vesicles with contents of different electron density are noted in many figures. The high incidence of small 80-200 nm vesicles is shown in Figures 3C and 3D. In Figure 3C, many vesicles indicated by small arrows are attached to a nearby bacteria or a membrane bound structure. Villus-like elements are at the extremity of lines departing from vl. Jam-like material is at the extremities of lines departing from the asterisk. In Figure 3D, the cytoplasmic profile at the left border of the figure contains a circular package of dense glycogen particles. In the enlarged images, it is possible to note bacteria profiles enmeshed with the numerous small vesicles and villus-like elements protruding from both exhibited cytoplasmic sectors. Small vesicles pointed by small arrows occupy the upper region of the figure. In Figure 3E, some bacterial profiles are marked with tiny white circles. The lower sized extremity of the bacterial profile marked with two asterisks contacts the jam-like material that fills a corner of a cytoplasmic fragment. The profile marked with one asterisk is an expansion of the jam-like material coating the cytoplasmic fragment surface. A comparable expansion from the cytoplasm coated by jam-like material marked by an asterisk in Figure 3F and whose base is indicated by two arrows is already a bacterium with a texture similar to other bacterial profiles as that enclosed by the upper dotted rectangle. This bacterial profile appears to have detached from a fitting nearby cytoplasmic depression. The bacterium-simile profile in the lower dotted rectangle pointed by the arrow appears to rest in a thin stripe of lucent substance that may be jam-like material.

Detachment of a cytoplasmic peripheral fragment and ensuing swelling predominantly originating spheroid bacteria in mycoplasma-infected cells

In Figure 4A, a massive cluster of typical bacteria appears by the side of a host cell cytoplasm whose border at left has a succession of smooth depressions. The arrow in the lower part of the figure points to a curved 

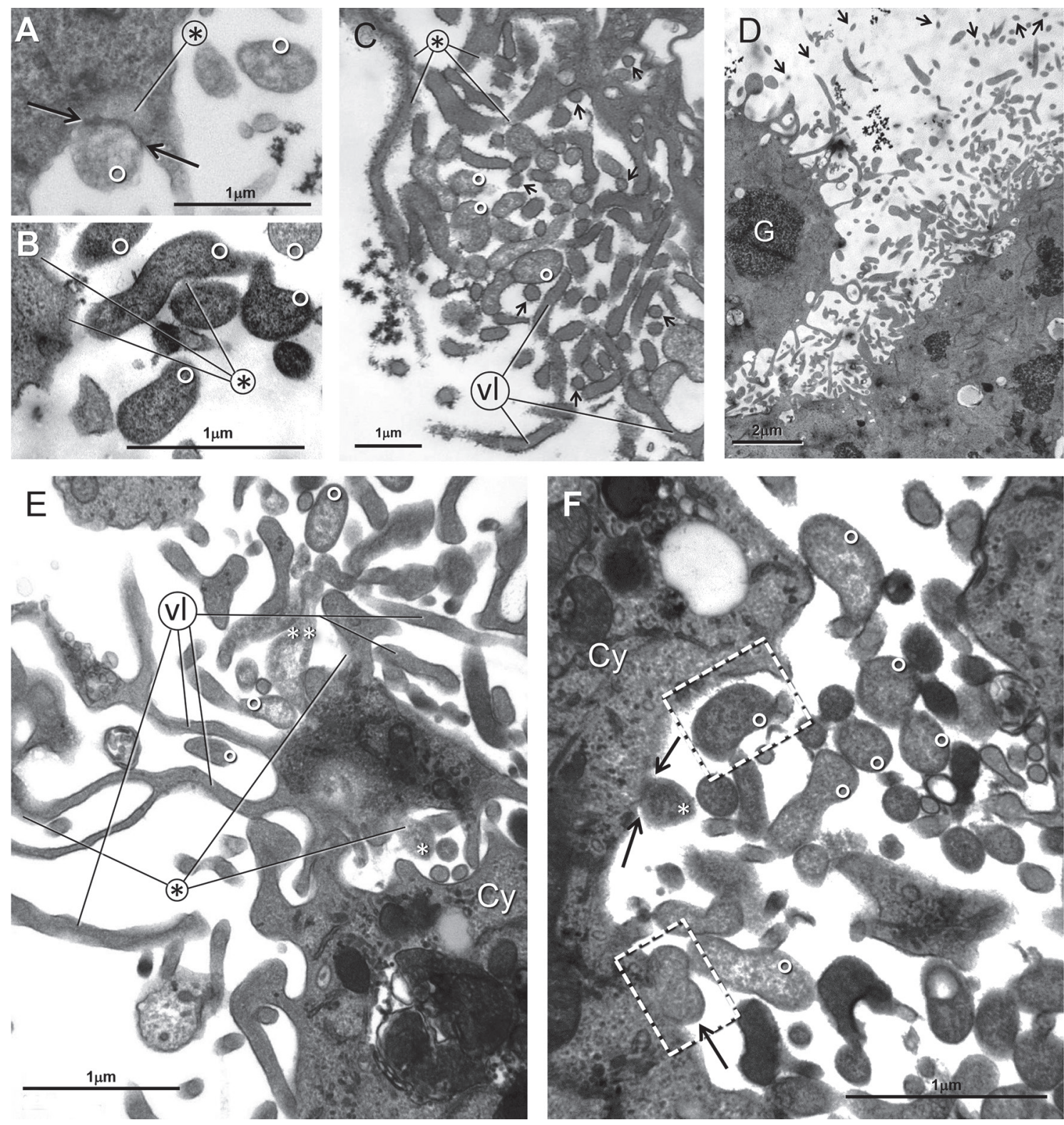

Figure 3 - Panels A, B and D are from sD - Staurosporine $0.4 \mu \mathrm{M} / 5 \mathrm{~h}$. Panels $\mathbf{C}, \mathbf{E}$ and $\mathbf{F}$ are from sC - Staurosporine $0.4 \mu \mathrm{M} / 5 \mathrm{~h}$. In Panel A a dense thin stripe (arrow at the extremities separates a jam-like region (asterisk) from a large adherent bacterium marked with a small white circle. In all panels - bacteria are marked by small white circles. In Panels $\mathbf{C}$ and $\mathbf{E}$ villus-like elements are marked as $\mathbf{v l}$ and in Panel $\mathbf{D}$ glycogen is marked as $\mathbf{G}$

profile that seems to have just detached from the nearby appropriate cytoplasmic depression. Possibly, part of the numerous bacteria close to the host cell derives from similar detachments of the peripheral cytoplasm. The other part derives from the ongoing division of the bacteria. Enclosed by dotted ellipsoids, there are curved dumbbell profiles, with this connecting intermediate rod, which probably represent binary division forms of mycoplasma. The analysis of some free dense bacilliform bacteria in the enlarged delimited square in Figure 4A (shown in Figure 4B) may suggest that many of these profiles derive from detachment of villus-like formations or segments of the cytoplasmic border with size and shape of bacillus and somewhat later, undergo progressive swelling. In the upper cell border of the Figure $4 \mathrm{~B}$, the cytoplasmic appendage numbered as 2 is slightly less dense than the villus-like structure just below, numbered as 1 . The arrow in the dotted rectangle points to the separation slit that released the appendage (numbered as 2) cell from the host cell. This appendage membrane has rapidly lost the former non-permeability condition to water carrying ions. The typical spheroidal bacterial profiles of mycoplasma (profiles numbered as 4 and 5) have a dense sub-membrane periphery and a clear center. On the right in Figure 4B, the normal cytosol of the host cell appears 


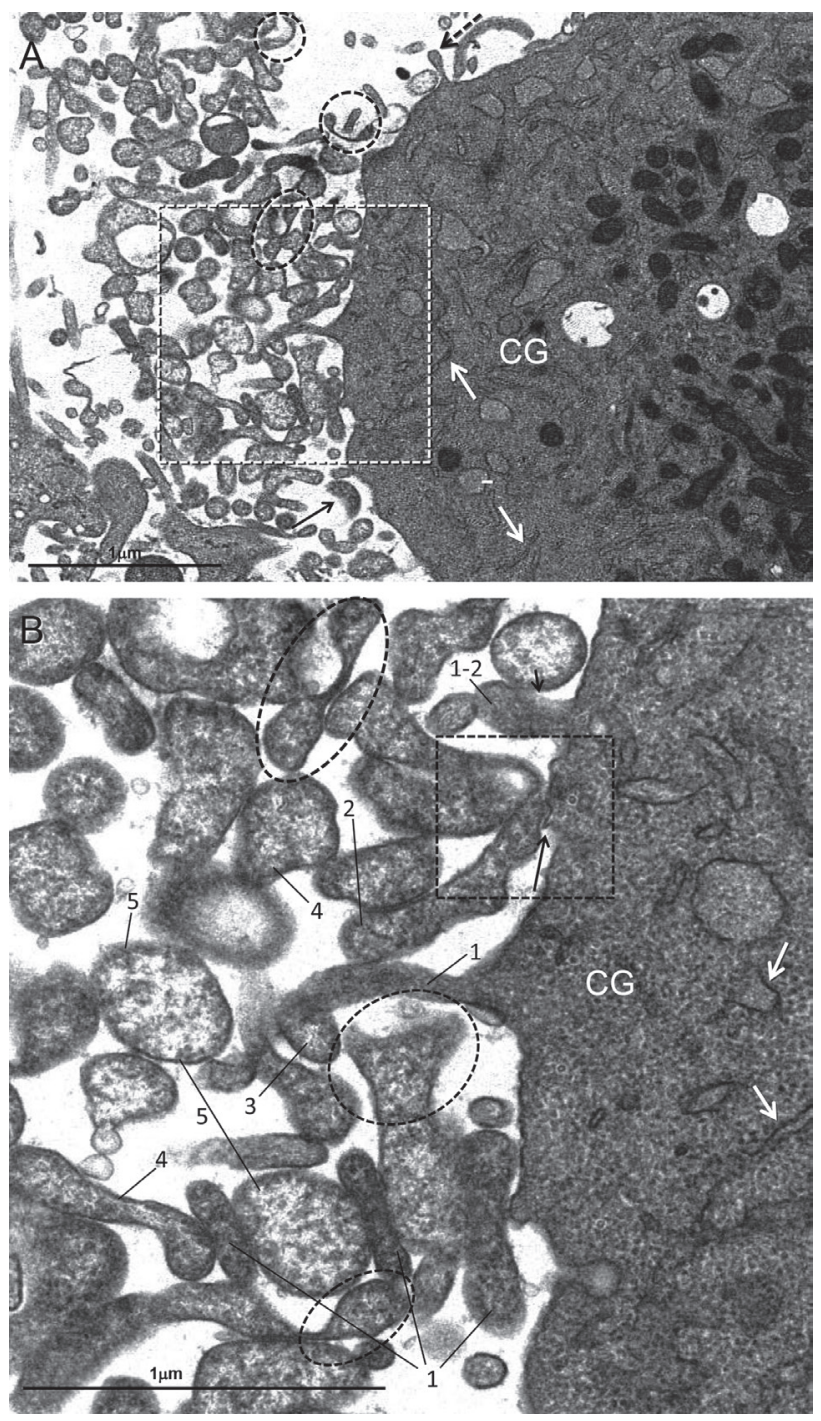

Figure $4-\mathrm{sB}$ cells treated with $0.1 \mu \mathrm{M} / 4 \mathrm{~h}$ staurosporine. Panel B is an enlarged sector from Panel A. Panel A: A detached curved bacterium-like profile apparently detached from a curved nearby depression of the host cell cytoplasm (black arrow). In panels A and B short segments of the endoplasmic reticulum cisternae (white arrows) and regions -of compact granular material that replaces the normal citosol (CG)

replaced by a compaction of small granules (CG) that has sparse short cisternae of the endoplasmic reticulum. In the lower part of the figure, putative detached dense bacilliform segments of the peripheral cytoplasm are at the extremities of lines departing from number 1 . The content of such structures is indistinguishable from that of the nearby cytoplasm. These structures, unlike all the others nearby, have not yet underwent swelling. It is unclear whether the original host cell membrane of the detached bacilliform cytoplasm does not acquire permeability characteristics immediately after separation from the donor compartment, whereby it allows the entrance of water carrying ions. Structure 1-2 is a small vesicle connected by the jam-like material to the cytoplasm.
Endoplasmic reticulum cisternae are indicated by arrows, ER. The dotted ellipsoid encloses the extremity of a former presumable villus-like element that has detached, carrying the cytoplasmic base pedestal and undergoing swelling. The villus-like structure number as 1 may be looked at as a horizontal $Y$ turned to the right with its pedestal bifurcation being still a component of the cytoplasm. Free inverted swollen Y profiles originated from disconnected pedestalcarrying-villus-like elements (enclosed by dotted line in Figure 2A) are relatively common close to bacteria.

In visibly infected cells from donor $\mathrm{D}$, undersized bacteria-like profiles are eventually noted. In Figure 5A, the ellipsoidal dotted lines on the right and center enclose vesicles that seem to precede in size those inside the closed dotted line at left. Vesicles of the latter group bear resemblance with bacteria. The adjacent, lesioned cytoplasm shows a markedly altered inter-membranous cytosol region represented by a compact granularity (CG) where several mitochondria lie with clear central regions (white arrows) adjoined by few stripes of short, thin endoplasmic reticulum cisternae. From the asterisk in Figure 5A, deriving lines that touch the remnants of the jam-like material possibly coating the surfaces of the now disjointed part of the cytoplasm have undergone separation from the cell. Figure 5B exhibits a crista-less mitochondrion undergoing divisional fission (asterisks). The dotted arrow indicates the region where the fission process of the mitochondrion is occurring. The arrows point to lucent mitochondria profiles containing vestiges of cristae. The finding of such mitochondrial profile devoid of cristae is first shown here. It is unique. The fact that it can undergo fission, like normal mitochondria do, leads to conjectures that will be discussed later.

In most preparations examined under the transmission electron microscope, notably in those with cells exposed to staurosporine, an insofar not described cell phenotype has appeared. It has cytoplasmic regions of various extensions, eventually filling the entire or most of the cytoplasmic space (Figures 6A and 6F) with tightly adjoined vacuoles with smooth inner membrane faces. These conferred a netlike appearance to that cytoplasmic region with circular, elongated worm-like or ovoid profiles. In the bottom part of Figure 6A, a sector of the parallel bundles of clear material running inclined from left to upper right is enclosed by a dotted rectangle. The enlarged rectangle contains faggots of probable cytoskeletal structures. The light material filling the vacuoles is often removable during the processing stages of dehydration and embedding. Perhaps these vacuolated cells are lighter than the other non-vacuolated cells, for their incidence increases in the pelleted supernatant of the culture flask with infected cells. This procedure helped to establish that apparently normal bacterial forms of mycoplasma are 


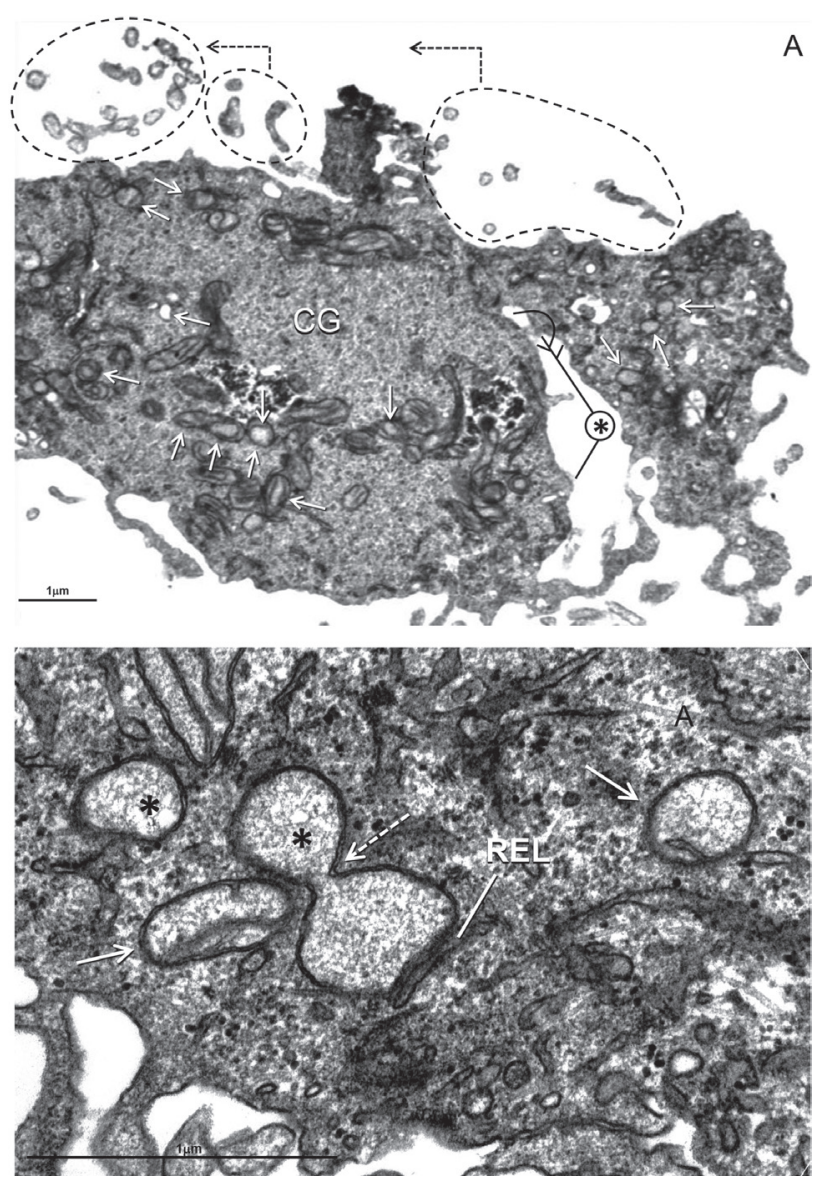

Figure 5 - Panel A - sD- Staurosporine $0.1 \mu \mathrm{M} / 6 \mathrm{~h}$ - Markedly altered cytoplasm, mostly represented by a compact granularity (CG) material replacing the cytosol, with a large part OF its right region undergoing separation from the cell. The lines departing from the asterisk terminate in regions were residual jam-like material may be perceived. Panel B - sD $0.2 \mu \mathrm{M} / 6$ h. Asterisks mark mitochondria profiles devoid of cristae. The large profile is undergoing fission. The doted arrow indicates where division will occur. Arrows point to mitochondrial profiles containing residual cristae

formed inside the vacuoles (enlarge Figure 6A to at least $200 \%$ ). Enclosed by dotted ellipsoids are differently shaped bacteria profiles. Note also the bacteria marked with small white circles in Figures 6B-6E and 6G. In the upper center of Figure $6 \mathrm{C}$, there is a not rare division form of bacteria. Figure 6D reveals a large vacuole containing differently shaped bacteria. Enclosed by a dotted line in the cytoplasm of the cell in Figure 6F there is a dumbbell-like mycoplasma that is enlarged in Figure 6G.

In the center of Figure 7, two parallel dotted arrows indicate the original lodging site from which the bacterium marked as b is disconnecting. The partition is occurring on the left extremity of the bacterium that is still coated with jam-like material. This bacterium formerly fitted completely within the regions denoted by the two dotted arrows. The thick arrowhead points to a mycoplasma that resembles the
Mycoplasma hyorhinis shown in Figure 1 -from Kornspan et al. ${ }^{19}$. The dense thin strip of material marked by the vertical arrows enclose a group of newly-formed bacteria. A similar thin dense belt indicated by the lower horizontal arrow has a coat of jam-like material. The profile occupying the vacuole inside the central dotted rectangle (enlarged in the upper left corner of Figure 7) is attached on the right to a dense stripe that separates it from the lighter band of jam-like material. The dense stripe denoted by the two small arrows in the upper enlarged rectangular sector resembles the dense stripe highlighted by the small arrows inside the right dotted rectangle. Both stripes of dense material seem to be adhering to pre-emerging bacteria. The beehive-like cytoplasmic spaces in the lower left cytoplasm may support this possibility. The quasi net-like disposition of the area encircled by the dotted line in the lower periphery of the cell in Figure 7 suggests that this cell is a modified host cell in an early formation stage, which is spurting a bunch of bacteria. All of them in the same structural developmental stage. Furthermore, the dense, thin band structures highlighted by the dotted arrows and the vertical and horizontal arrows to which the nascent bacteria inside the two dotted rectangles of Figure 7 are adhering, are part of a structure built by the host cell to lodge and generate mycoplasma. The thick clear band of material in the upper part of Figure 7 marked as $\mathbf{F}$ contains filamentous material disposed in parallel. They may be intermediate filaments. Thus, it seems that the appearance of modified host cells, not necessarily relies on the presence of mycoplasma.

\section{PCR and sequencing data}

Amplification results of genomic DNA and testing for the presence of mycoplasma are shown in Figure 8A. All three tested samples demonstrated very strong positive reactions for the presence of mycoplasma. Further sequencing of the samples revealed that the three examined samples from donors B, C and D carried M. hyorhinis (Figure 8B). The ensuing repetitions of PCR only with cells from each of the donors were performed in 2015 and 2016. In 2017 thawed samples from another batch of cells from donor B, one in whom no typical bacteria were detected, gave negative PCR results, despite the fact that among the cells with structural signs of cytoplasmic lesions, cells were present.

\section{DISCUSSION}

The observed fine structural lesions induced by mycoplasma in host cells expand upon those shown by Nir-Paz et al. ${ }^{5}$, Kornspan et al. ${ }^{19}$ and Sesso et al. ${ }^{16}$ and revealed undescribed structural components of the 

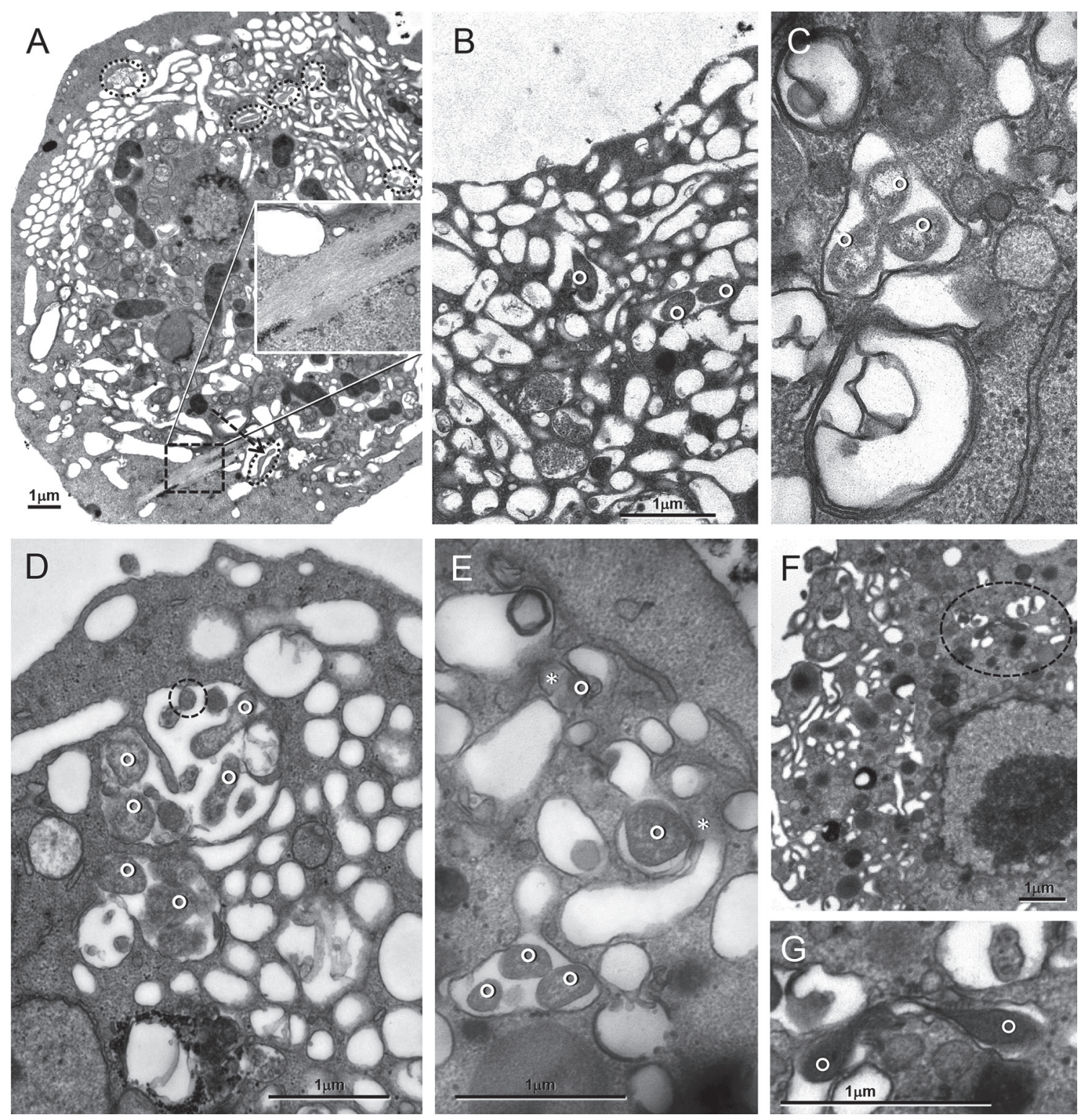

Figure 6 - Panels A and B are from sD $0.2 \mu \mathrm{M} / 6 \mathrm{~h}$ and sB $0.5 \mu \mathrm{M} / 6 \mathrm{~h}$, respectively. Panels $\mathbf{C}, \mathbf{D}$ and $\mathbf{F}$ are from sC $0.5 \mu \mathrm{M} / 5 \mathrm{~h}$. In enlarged Panel A it is noted that several vacuoles contain bacteria. Dotted lines enclose some of them. In the lower dotted ellipse, a dotted arrow points to the fission of the extremity of a bacterium. The inner section shows bundles of a material that seems to represent aggregation of former cytoskeletal structures. All bacteria are marked with small white circles. Bacterial forms that seem to be in the process of division are in Panel $\mathbf{C}$, in the center vacuole in Panel $\mathbf{D}$, in the largest vacuole - in Panel $\mathbf{G}$ (which is an enlarged sector of Panel F). In Panel E, asterisks mark a homogenous material that may be residuos of the former content that filled the vacuole

infected cells cytoplasmic dismantling. As for the novel findings, here we comment mainly the appearance of new bacteria on the host cell surface and the finding of the cells. Additional information on 80-200 nm diameter vesicles, on the villus-like elements and on the crista-less mitochondria will appear soon. Part of the bacteria shown in Figures 2A, 2B, 4A and 4B derive from local division as indicated by the several dumbbell-like profiles, and another part arises locally from the cell surface. The mechanisms involved in Figures 2 and 4 are similar, but apparently not equal. In both cases, the border cytoplasm and the new forming bacteria content is of compact granularity. In the case of Figure 2, bacteria has probably arisen from emerging dense villus-like projections from the cell surface. In 4, bacteria derived from villus-like elements,mainly from frequent detachments of bacilliform segments in the peripheral cytoplasm. In both cases, swelling of the cytoplasmic parts detached from the host cell occurs. In case of Figure 2, it seems that the structural scenario has favored the idea that bacteria derive from detached dense villus-like elements. It is difficult to 


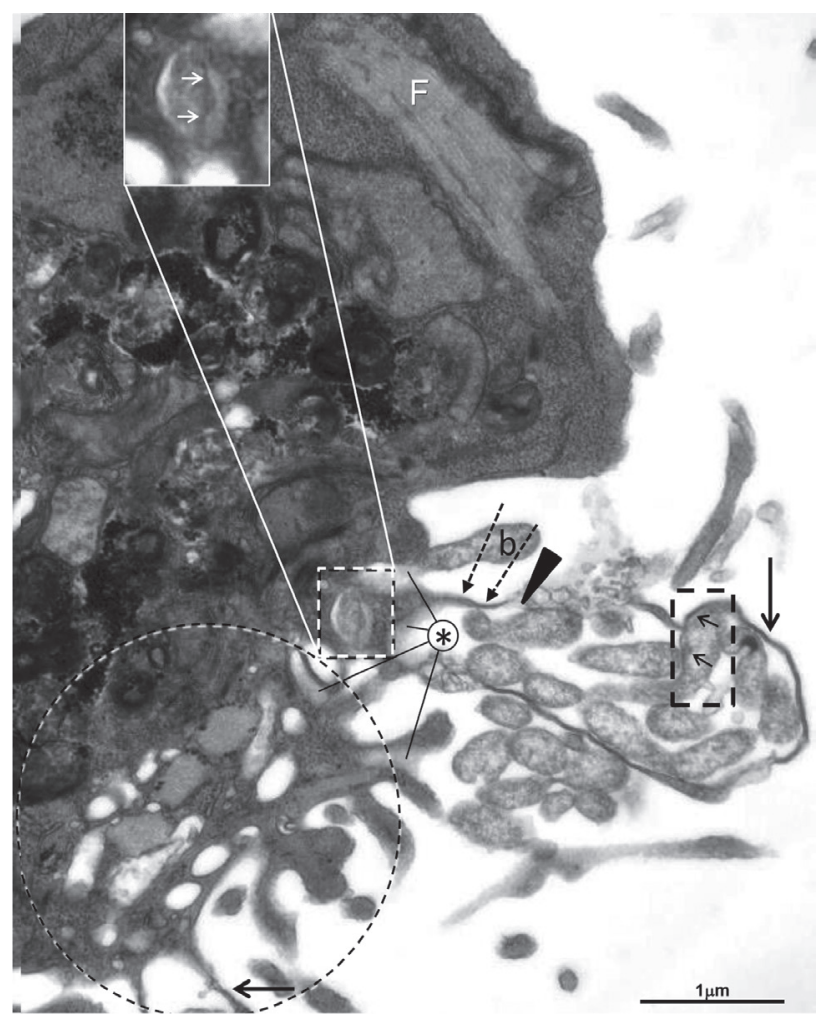

Figure 7 - Cell from $\mathrm{sC}$ exposed to $0.5 \mu \mathrm{M} / 5$ h staurosporine. Adjoining partially filled vacuoles of the net-like sector of the cell (dotted circle at the lower left). - In the middle intermediate region one notes "en bloc" discharge of bacteria. Growing bacterial forms adhered to a strip of dense material (two central and the enlarged upper rectangles. - This dense stripe is similar to the dense stripe -on the right indicated by the vertical arrow. The same thin dense band adhering to a bacterium is also in the right rectangle. Thin dense strip of material (vertical arrow). Horizontal arrows point to a region with inter-vacuolar cytoplasm (horizontal arrow)

interpret otherwise the presence of the swollen elongated profiles (as those indicated by the interrupted parallel lines 2 and 4 , and that marked by $3 \mathbf{a}$ and $\mathbf{b}$, and other elongated bacterial profiles) and the apparently newly-formed swollen villus-like elements pointed by dotted arrows. Yet, the possibility of an eventual unnoticed alternative explanation cannot be ruled out.

The detachment of peripheral cytoplasmic pieces that fit precisely in the nearby slightly curved depression of the host cell border (arrow in Figure 4A and upper dotted rectangle in Figure 3F) and the host cell borders showing successive slight curved depressions (Figures 2C, 3F and 4A) are pieces of evidence of the cytoplasmic origin of these bacteria.

All elongated, curved or not, swollen profiles seen in Figures $2 \mathrm{~A}$ and $4 \mathrm{~A}$ will end up assuming the spheroid form. In some of the villus-like elements, prior to complete detachment, their membranes allow the entrance of water carrying ions (dotted arrows in Figure 2A). Regarding

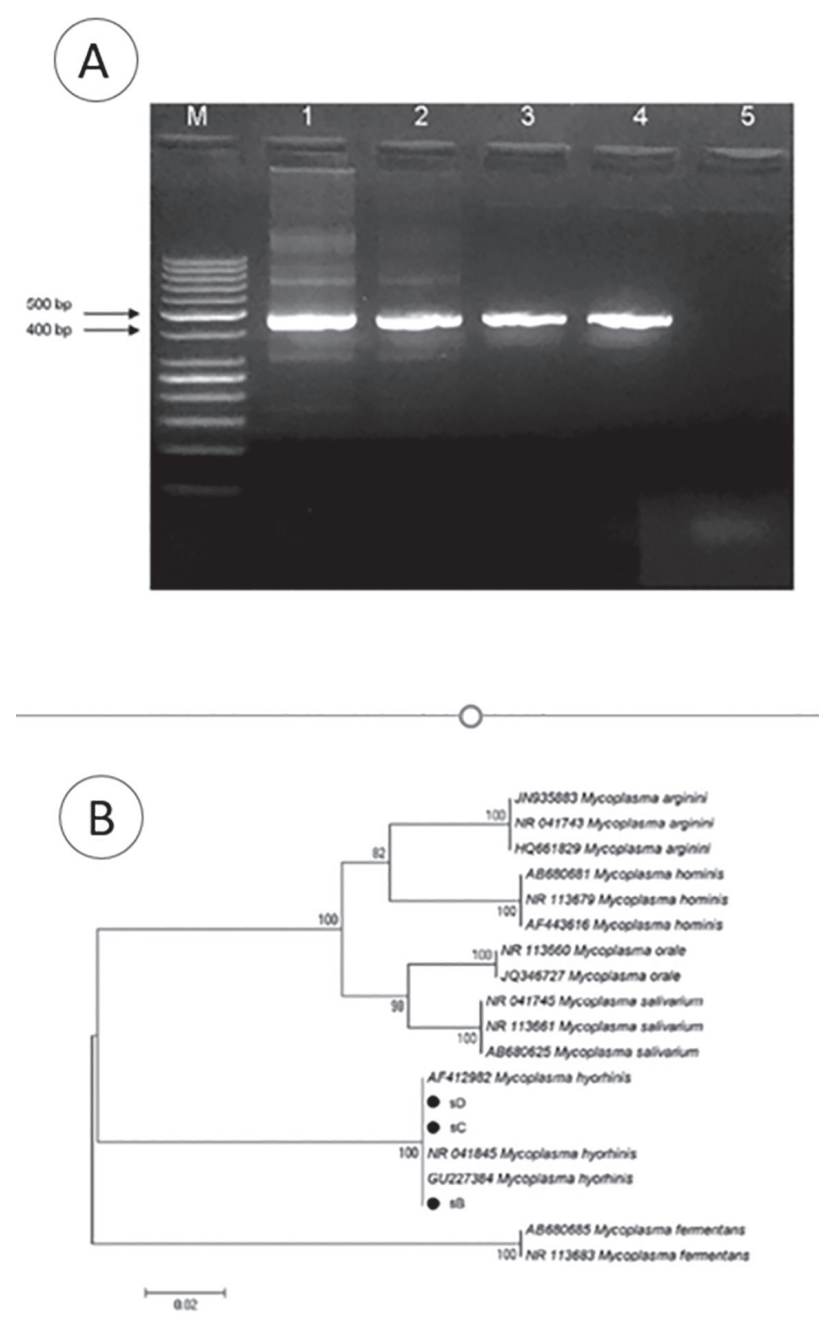

Figure 8 - A - Agarose gel electrophoresis of 16S rRNA amplicons. Lane 1, 2 and 3: positive samples (HeLa cells sB, sD and SC, respectively). Lane 4: Positive control (464-bp band, $M$. arginini from ATCC Universal Mycoplasma Detection Kit). Lane 5: Negative control. M: -Molecular weight marker (GeneRuler 50 bp DNA Ladder, Thermo Scientific). B. Phylogenetic tree based on the comparative analysis of the 16S rRNA gene sequences using the Neighbor-joining ( $\mathrm{NJ}$ ) method. Bootstrap percentages based on 1,000 replications are shown on branch nodes

the other similar mechanism, bacillus-like portions of the peripheral cytoplasm detached and started swelling either from the moment of disconnection from the donor cytoplasm (profile numbered as 2 in Figure 4B) or perhaps later on, when the detached portions are to some extent distant from the host cell donor cytoplasm (profiles numbered as 1, lower part of Figure 4B). The appearance of newly-formed bacteria, in Figure 2C and in all panels of Figure 3, reveals a close structural proximity between the nascent bacteria and the jam-like material coating the cytoplasmic surface from which the bacteria derived. Jam-like material also coats totally or partially bacteria adherent to the cytoplasm, for example, the bacterium with two asterisk in 3E. Possibly the profile marked with 
one asterisk in Figure $2 \mathrm{C}$ is in a developmental stage that precedes the successive maturation stages appearing consecutively marked with one asterisk in Figures $3 \mathrm{E}$ and 3F. In Figure 3F, the bacterium with asterisk is formed. Yet, its precise nature cannot be determined, as well as its size and arriving route of the material that will grow as a bacterium inside or attached to the jam-like material as seen in Figures $2 \mathrm{C}$ and $4 \mathrm{~A}-4 \mathrm{~F}$. This bacterial growth associated with jam-like material may coexist with the mechanism of detachment of bacterium shaped and sized as cytoplasmic fragments, as shown in Figure $3 \mathrm{~F}$ by the profiles inside the upper dotted rectangle and that marked with one asterisk and two arrows, respectively. In the formation of bacteria in Figures 2A, 2B, 4A and 4B and inside the upper dotted rectangle in Figure 3F, all substances were formed and derived from the compact granularity of the host cell peripheral cytoplasm. In this case, we are forced to assume that the mycoplasma genome is contained in this compact granular material. The host cell membrane's normal impermeability to external water, in some instances, in both Figures 2A and 4A, is lost immediately after detachment of the fragment that will become bacteria. Changes in membrane permeability of the new detached bacteria derive from the following causes: a) the compact granular material has a high colloid osmotic pressure that cannot express itself through the host cell membrane; b) when the bacterium separates from the cytoplasm, the membrane surrounding the segment that formerly belonged to the host cell acquires different permeability conditions, allowing the entrance of water carrying ions. The selective permeability of the plasmalemma, in the case of the villus-like protrusion marked as 2 in Figure 4B, is lost when the cytoplasmic protrusion is disconnected from the cell. In other instances, it may occur somewhat later. This loss of selective permeability bears resemblance with that occurring in the inner mitochondrial membrane entering the transition phase of permeability conditions. When the inner mitochondrial membrane loses its selective permeability, the mitochondrial matrix which has one of the major protein concentrations, thus, a high colloid osmotic pressure undergoes a marked swelling that enlarges the inner mitochondrial compartment to the point of rupturing the external mitochondrial membrane. This relates to the fact that, in some instances, the bacterial swelling transforms the bacterium in large spheroid bodies. The same change in permeability is visible in Figure 2A after the villus-like structure disconnects from the infected cytoplasm and swells to assume a bacterial format. It is unclear whether the observations in Figures 2 and 3 are associated with the results of Hopfe et al. ${ }^{11}$ that in markedly mycoplasma-infected HeLa cells claimed that
" $M$. hominis-filled protrusions of the host cell membrane were seen by confocal microscopy, suggesting exocytotic dissemination". The image in Figure 2B, which is partially enlarged from Figure 2A, represents an extreme case of parasitism of a living entity. In this situation, one has the impression that the cell was kept alive with a thin rim of cytoplasm and with large nucleoli suggesting intense synthesis of RNA, as a supplier of material for the generation of bacteria.

\section{Host cell-parasite interaction}

The phenotypic differences between the peripheries of the mycoplasma-contaminated cells noted in the cells from the same culture and in cells from different cell donors, as well as the variations in the expression of mycoplasmainduced structural cytopathic lesions, derive from many causes. Among these, there are previous protocols of cell culture maintenance and subsequent antibacterial treatments. Of note is the fact that, in some cultures of mildly infected cells, staurosporine $0.1 \mu \mathrm{M} / 6 \mathrm{~h}$ promoted $15-25 \%$ of apoptotic cell death, while, in visibly infected cells, the same staurosporine treatment promoted apoptotic indices of $40-53 \%$. The marked differences noted in the effects of the lower staurosporine concentrations derive from differences in the status of host-parasite interactions. The resulting effects depend on which of the two involved mechanisms, either survival of the mycoplasma or of the host cell defense, will prevail. If the host cell defenses outweights the host-parasite interactions, the cells, as noted in those initially examined from donor A1 treated with $0.1 \mu \mathrm{M}$ staurosporine for $6 \mathrm{~h}$, exhibit infrequent minor losses of peripheral cytoplasmic material as villi or small irregular fragments. Thus, this cell culture contained, among the infected cells, a minimal fraction of staurosporine-sensitive cells. The most complete control of the host cell by the mycoplasma occurred in a cell not exposed to staurosporine (Figures 2A and 2B).

\section{Mycoplasma can modulate the activity of cytokine pathways and genes of the host cell}

Mycoplasma can alter the activity of the complex signaling network of kinases ${ }^{20}$. Blocking this signaling mechanism by staurosporine explains why this drug induces an imbalance or enhances a previous imbalance of the host-parasite relationship by diminishing the host cell defenses. A growing number of observations has revealed that mycoplasma infections favor the malignant transformation of cells. Long-term mycoplasma infection of cultured cells was associated with chromosomal instability 
and promoted malignant transformation ${ }^{21-23}$. Persistent infections with $M$. genitalium and $M$. hyorhinis induced malignant transformation of benign human prostate cells BPH-1 ${ }^{24}$. M. genitalium infection promoted upregulation or downregulation of groups of genes related to host cell defenses and encoding pro-inflammatory cytokines ${ }^{25}$. Differential expression, i.e., depression or stimulation of genes related to cell proliferation, immune responses, cell kinase systems, cell proliferation and cell death, occurs in HeLa cells infected with M. hominis. The number of altered genes increases from 723 at $4 \mathrm{~h}$ to 1588 at $48 \mathrm{~h}$ post-infection ${ }^{11}$. M. hyorhinis and M. fermentans can degrade the host cell genome, altering the gene expression linked to tumorigenesis, cell proliferation, lysosomal activity, cell metabolism and signaling pathways ${ }^{26}$. The observed differences in phenotypes among HeLa cells received from some donors and occurring in successively sub-cultured cells from the same donor may also be due to mutations in the genome of the infecting mycoplasma ${ }^{27,28}$. The host cell changes and generates villus-like elements that, upon disconnection, turn into bacteria (Figures 2A and $2 \mathrm{~B}$ ); however, this cannot be completely explained as a consequence of some genes depressed activityand enhancement of other genes activity in the host cell. One can imagine a complete depression of the genes involved in cell defense, a real possibility. It is unknown whether the mechanisms include alterations involving both genes of the host cell and genes of the parasite in an unknown series of events, perhaps similar to the situation referred to by Liu and Shou $^{26}$ as degradation of the cell genome and dysregulation of gene expression. We do not know whether and to what extent the nucleic acids of the infecting mycoplasma may have interacted with the structural synthesis machinery of the host cell. It is conjectural whether, in some cases, mycoplasma DNA could be transferred to the genome of HeLa cells, as it has now been shown that bacterial DNA may be incorporated into the human genome, namely, in cancer cells ${ }^{29}$.

M. hominis that survives inside HeLa cells co-localizes with lysosomal proteins ${ }^{11}$. The images we observed of nascent bacteria forms inside modified host cells vacuoles suggest that these vacuoles are outside the reach of host cell's endosomal-lysosomal defense mechanisms. Yet, the origin of the membrane vacuoles is undetermined and further observations are necessary. Chernov et al..$^{30}$ noted that, depending on the status of the cell DNA methylation, M. hyorhinis "efficiently evaded endosomal degradation and uses exocytosis to exit infected human cells".

Jam-like material seems to be present in some published transmission electron micrographs of mycoplasma-infected cells, as shown in Figure 2D from Nir-Paz et al. ${ }^{5}$, in
Figure 1 (inset at lower left) from Korspan et al. ${ }^{19}$, and in Bürki et al. ${ }^{4}$ On the surface of $M$. pneumoniae-infected neuroblastoma cells, what seems to be jam-like material, appears intertwined or enmeshed with dense aggregates of rod-like resembling villus-like structures. Such villus-like structures emerge from the infected cytoplasm. Among these, there are vesicles approximately $80 \mathrm{~nm}$ in diameter (Figure 4A in Meseguer et al. ${ }^{31}$ ). The consistent presence of jam-like material in all structural cytopathic events of cytoplasmic degradation is remarkable. Regarding the jam-like material, one point that needs to be clarified is the precise role it plays in the generation and growth of bacterial forms of mycoplasma (Figures 2C and Figure 3) that appear attached to the cell surface and often more or less enveloped by this material.

\section{CONCLUSIONS}

To generate a modified host cell, the parasite must encounter a favorable environment so that it ultimately controls the host cell synthesis machinery. The smooth membrane of the adjoining vacuoles, disposed as a net, is a smooth membrane synthesized due to the presence of parasite. This membrane produces the processing-sensitive clear material that fills the host cell vacuoles and inside which parasite will appear.

The observations of mycoplasma entering and surviving in the cytoplasm ${ }^{4,8,9}$ being eventually extruded at the cell periphery ${ }^{11}$ were reported using fluorescent mycoplasma markers and fluorescent confocal microscopy. Bürki et al. ${ }^{4}$, using transmission electron microscopy, noted a bacterial vesicle of $M$. bovis close to the host cell border, with $230 \mathrm{~nm}$ diameter inside a vacuole that may belong to the endosomal system because of its membrane's particular coating. In the case of Mycoplasma genitalium, it also survives and multiplies intracellularly ${ }^{32}$ in large vacuoles of the host cell cytoplasm, whose membranes exhibit no coating at all.

In all the observations insofar carried out with the transmission electron microscope, not even the slightest indication that typical bacteria could penetrate and multiply in the host cell has ever appeared. Pertinent questions on this issue are: what is the structure of the infective form of mycoplasma, how it penetrates and eventually transits inside the host cell.

\section{FUNDING}

This study was supported by the Fundação de Amparo à Pesquisa do Estado de São Paulo (FAPESP) - Processo $\mathrm{N}^{\mathrm{o}} 2013 / 22.816-2$. 


\section{REFERENCES}

1. Nocard E, Roux E. The microbe of pleuropneumonia: 1896. Rev Infect Dis. 1990;12:354-8.

2. Razin S, Hayflick L. Highlights of mycoplasma research - an historical perspective. Biologicals. 2010;38:183-90.

3. Boatman E, Cartwright F, Kenny G. Morphology, morphometry and electron microscopy of HeLa cells infected with bovine Mycoplasma. Cell Tissue Res. 1976;170:1-16.

4. Bürki S, Gaschen V, Stoffel MH, Stojiljkovic A, Frey J, KuehniBoghenbor K, et al. Invasion and persistence of Mycoplasma bovis in embryonic calf turbinate cells. Vet Res. 2015;46:53.

5. Nir-Paz R, Prévost MC, Nicolas P, Blanchard A, Wróblewski H. Susceptibilities of Mycoplasma fermentans and Mycoplasma hyorhinis to membrane-active peptides and enrofloxacin in human tissue cell cultures. Antimicrob Agents Chemother. 2002;46:1218-25.

6. Razin S, Argaman M, Avigan J. Chemical composition of Mycoplasma cells and membranes. J Gen Microbiol. 1963;33:477-87.

7. Xiao JX, Huang GQ, Zhu CP, Ren DD, Zhang SH. Morphological study on apoptosis Hela cells induced by soyasaponins. Toxicol In Vitro. 2007;21:820-6.

8. Baseman JB, Lange M, Criscimagna NL, Giron JA, Thomas CA. Interplay between Mycoplasmas and host target cells. Microb Pathog. 1995; 19:105-16.

9. Winner F, Rosengarten R, Citti C. In vitro cell invasion of Mycoplasma gallisepticum. Infect Immun. 2000;68:4238-44.

10. Kikkawa S, Matsumoto M, Sasaki T, Nishiguchi M, Tanaka K, Toyoshima K, et al. Complement activation in Mycoplasma fermentans-induced mycoplasma clearance from infected cells: probing of the organism with monoclonal antibodies against M161Ag. Infect Immun. 2000;68:1672-80.

11. Hopfe M, Deenen R, Degrandi D, Köhrer K, Henrich B. Host cell responses to persistent mycoplasmas-different stages in infection of HeLa cells with Mycoplasma hominis. PLoS One. 2013;8:e54219.

12. Tully JG. Newly discovered mollicutes. In: Razin S, Barile MF, editors. Mycoplasma pathogenicty. Orlando: Academic Press; 1985. p.1-26.

13. Frerichs GN. Identification and elimination of mycoplasmas in fish cell line cultures. J Fish Dis. 1996;19:435-9.

14. Garnier M, Foissac X, Gaurivaud P, Laigret F, Renaudin J, Saillard C, et al. Mycoplasmas, plants, insect vectors: a matrimonial triangle. C R Acad Sci III. 2001;324:923-8.

15. Franke WW, Scheer U. Some structural differentiations in the HeLa cell: heavy bodies, annulate lamellae, and cotte de maillet endoplasmic reticulum. Cytobiologie. 1971;4:317-29.

16. Sesso A, Yamashiro-Kanashiro EH, Orii NM, Taniwaki NN, Kawakami J, Carneiro SM. Loose and compact agglomerates of $50 \mathrm{~nm}$ microvesicles derived from Golgi and endoplasmic reticulum membranes in pre- and in -apoptotic mycoplasma infected HeLa cells: host-parasite interactions under the transmission electron microscope. Rev Inst Med Trop São Paulo. 2015;57:89-91.

17. Saitou N, Nei M. The neighbor-joining method: a new method for reconstructing phylogenetic trees. Mol Biol Evol. 1987;4:40625.

18. Vollenbroich D, Pauli G, Ozel M, Vater J. Antimycoplasma properties and application in cell culture of surfactin, a lipopeptide antibiotic from Bacillus subtilis. Appl Environ Microbiol. 1997;63:44-9.

19. Kornspan JD, Tarshis M, Rottem S. Invasion of melanoma cells by Mycoplasma hyorhinis: enhancement by protease treatment. Infect Immun. 2010;78:611-7.

20. Rottem S, Naot Y. Subversion and exploitation of host cells by mycoplasmas. Trends Microbiol. 1998;6:436-40.

21. Huang S, Li JY, Wu J, Meng L, Shou CC. Mycoplasma infections and different human carcinomas. World J Gastroenterol. 2001;7:266-9.

22. Tsai S, Wear DJ, Shih JW, Lo SC. Mycoplasmas and oncogenesis: persistent infection and multistage malignant transformation. Proc Natl Acad Sci U S A. 1995;92:10197-201.

23. Zhang S, Tsai S, Wu TT, Li B, Shih JW, Lo SC. Mycoplasma fermentans infection promotes immortalization of human peripheral blood mononuclear cells in culture. Blood. 2004;104:4252-9.

24. Namiki K, Goodison S, Porvasnik S, Allan RW, Iczkowski KA, Urbanek C, et al. Persistent exposure to Mycoplasma induces malignant transformation of human prostate cells. PLoS One. 2009;4:e6872.

25. McGowin CL, Radtke AL, Abraham K, Martin DH, HerbstKralovetz M. Mycoplasma genitalium infection activates cellular host defense and inflammation pathways in a 3-dimensional human endocervical epithelial cell model. J Infect Dis. 2013;207:1857-68.

26. Liu W, Shou C. Mycoplasma hyorhinis and Mycoplasma fermentans induce cell apoptosis and changes in gene expression profiles of 32D cells. Biol Res. 2011;44:383-91.

27. Yogev D, Rosengarten R, Watson-McKown R, Wise KS. Molecular basis of Mycoplasma surface antigenic variation: a novel set of divergent genes undergo spontaneous mutation of periodic coding regions and 5' regulatory sequences. EMBO J. 1991;10:4069-79.

28. Yoo SJ, Kim HB, Choi SH, Lee SO, Kim SH, Hong SB, et al. Differences in the frequency of 23S rRNA gene mutations in Mycoplasma pneumoniae between children and adults with community-acquired pneumonia: clinical impact of mutations conferring macrolide resistance. Antimicrob Agents Chemother. 2012;56:6393-6.

29. Riley DR, Sieber KB, Robinson KM, White JR, Ganesan A, Nourbakhsh S, et al. Bacteria-human somatic cell lateral gene 
transfer is enriched in cancer samples. PLoS Comput Biol. 2013;9:e1003107.

30. Chernov AV, Reyes L, Peterson S, Strongin AY. Depletion of CG-specific methylation in Mycoplasma hyorhinis genomic DNA after host cell invasion. PLoS One. 2015;10:e0142529.

31. Meseguer MA, Alvarez A, Rejas MT, Sánchez C, Pérez-Díaz
JC, Baquero F. Mycoplasma pneumoniae: a reduced-genome intracellular bacterial pathogen. Infect Genet Evol. 2003;3:4755 .

32. Jensen JS, Blom J, Lind K. Intracellular location of Mycoplasma genitalium in cultured Vero cells as demonstrated by electron microscopy. Int J Exp Pathol. 1994;75:91-8. 